ORIGINAL STUDY

\title{
Some forensic aspects of the nasal septal deformities
}

\section{Ranko Mladina ${ }^{1}$, Neven Skitarelić ${ }^{2,3}$, Cemal Cingi ${ }^{4}$, Nuray Bayar Muluk ${ }^{5}$}

${ }^{1}$ The Board of Surgical Sciences, Croatian Academy of Medical Sciences, Zagreb, Croatia

${ }^{2}$ Department of Health Studies, University of Zadar, Zadar, Croatia

${ }^{3}$ Faculty of Medicine, University of Rijeka, Rijeka, Croatia

${ }^{4}$ ENT Head and Neck Surgery Department, Faculty of Medicine, Eskisehir Osmangazi University,

Eskisehir, Turkey

${ }^{5}$ ENT Head and Neck Surgery Department, Faculty of Medicine, Kirikkale University, Kirikkale, Turkey

\section{ABSTRACT}

OBJECTIVES. We reviewed the foreign aspects in nasal septal deformities.

MATERIAL AND METHODS. Mladina classification of the nasal septal deformities was used.

RESULTS. Types 5 and 6 have been dominantly inherited. The mechanism of the onset and possible connection to the trauma against the nose, as well as clinical implications of the remaining four types of the nasal septal deformities, have been explained and described in detail, giving the court expert witnesses the excellent opportunity to make a reliable and valuable finding.

CONCLUSION. Type 5 and type 6 nasal septal deformities are never the consequence of the trauma against the nose. In most of the cases, this also concerns type 3 . This type as well as type 7 require the latero-lateral and anterior-posterior X-rays of the nasal bones in cases when the nasal pyramid is concurrently deformed. Types 1 and 2 in most of the cases are connected to trauma against the nose.

KEYWORDS: nasal septal deformities, nasal trauma, court expert witness, forensic expertise.

\section{INTRODUCTION}

Nasal septal deformities do not appear chaotically and are not of variegated shapes. Mladina published his classification in the year $1987^{1}$. He described four socalled "vertical" types (types 1, 2, 3 and 4) and two socalled "horizontal" deformities (types 5 and 6 ). These six types are sometimes combined among themselves and then form the so-called type 7, which has a nickname "crumpled septum". It must be emphasized that the particular types of nasal septal deformities in man could slightly differ between each other, but the characteristic feature of the particular type is a backbone that every modern rhinologist and court expert witness should be able to instantly recognize. It is not at all enough to take a look into the nose by means of the nasal speculum and make any conclusions. Nowadays, rhinology strictly and strongly requires three steps in the examination of the nose, particularly for the court expert witness purposes: 1) native anterior rhinoscopy by means of the nasal speculum; 2) anterior rhinoscopy after the correct nasal decongestion; 3) nasal endoscopy after the decongestion and superficial local anaesthesia of the nasal mucosa. Nevertheless, the tools and most updated equipment are not sufficient for the correct examination of the internal nose, but, in the first place, the theoretical knowledge and a standardization of the morphological findings are needed.

It took more than ten years of intensive practical surgical work and parallel measurements as well as intraoperative observations until it became clear that type 5 (colloquially called "septal spur" in the literature) is in fact a homogenous, unilateral bony formation of the very posterior part of the nasal septum and, what is much more important, it has been noted that type 5 is a directly and dominantly inherited deformity! The same happened with type 6 . It has been shown that this type is also a dominantly inherited deformity and has nothing to do with any kind of trauma against the nose $\mathrm{e}^{2-5}$. 


\section{MLADINA CLASSIFICATION OF THE NASAL SEPTAL DEFORMITIES}

Type 1 means a mild unilateral vertical ridge in a valve area, which slightly interferes with the function of the nasal valve. Thus, in most of the cases, this type of nasal septum deviation has a mild clinical importance (Figure 1). Type $\mathbf{2}$ is represented by a unilateral vertical ridge, this time much more emphasized (i.e. it stays in a close contact to the anterior nasal valve and

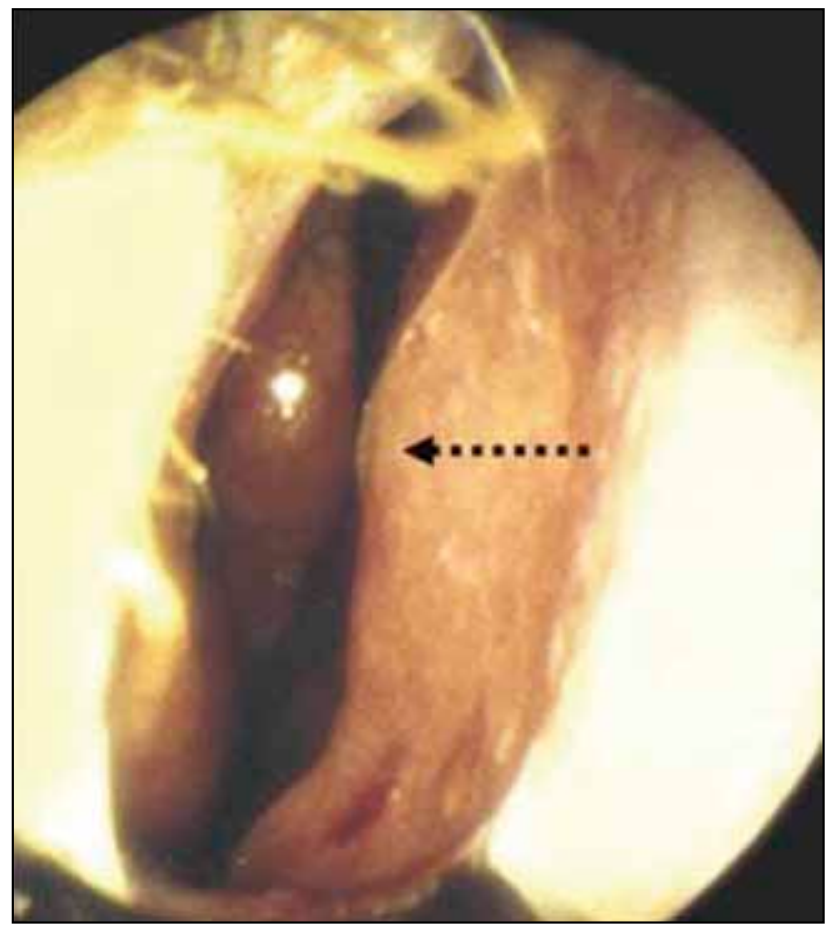

Figure 1 Right-sided type 1 nasal septal deformity (black dotted arrow).

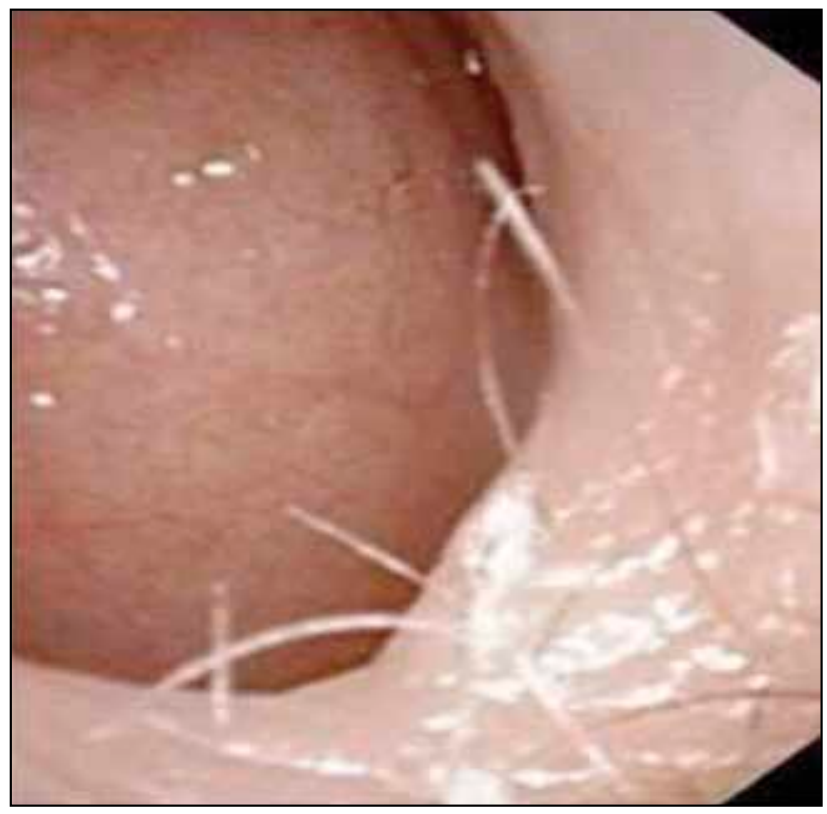

Figure 3 The left-sided type 2, which totally obstructs the entrance to the nasal cavity. thus, from the physical point of view, remarkably narrows or even totally blocks the air passage on the related nasal side) (Figures 2, 3, 4).

Type 3 means unilateral vertical deformity (i.e. unilateral convexity located in the middle of the nasal cavity, next to the anterior edge of the head of the middle turbinate) (Figure 5). The nasal cavity is very narrow on this side and very wide on the opposite one because of the correspondent septal concavity.

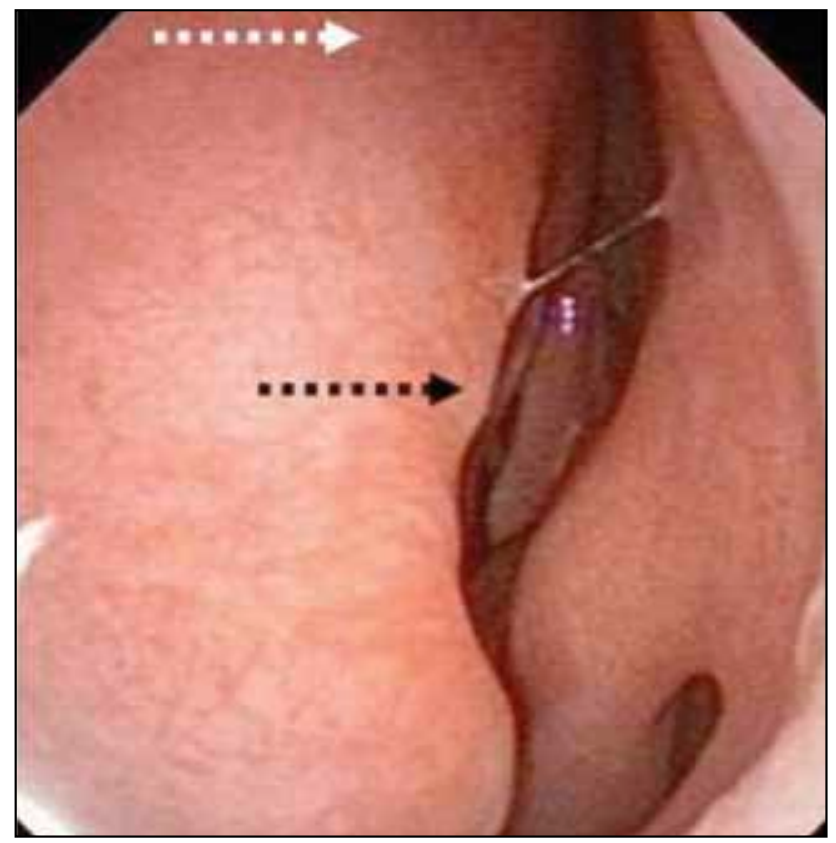

Figure 2 Left-sided septal deformity type 2 that remarkably narrows the entrance to the left nasal cavity (black dotted arrow). Still, the inferior turbinate can be followed almost all the way to the choana. The anterior half of the middle turbinate can be easily seen as well.

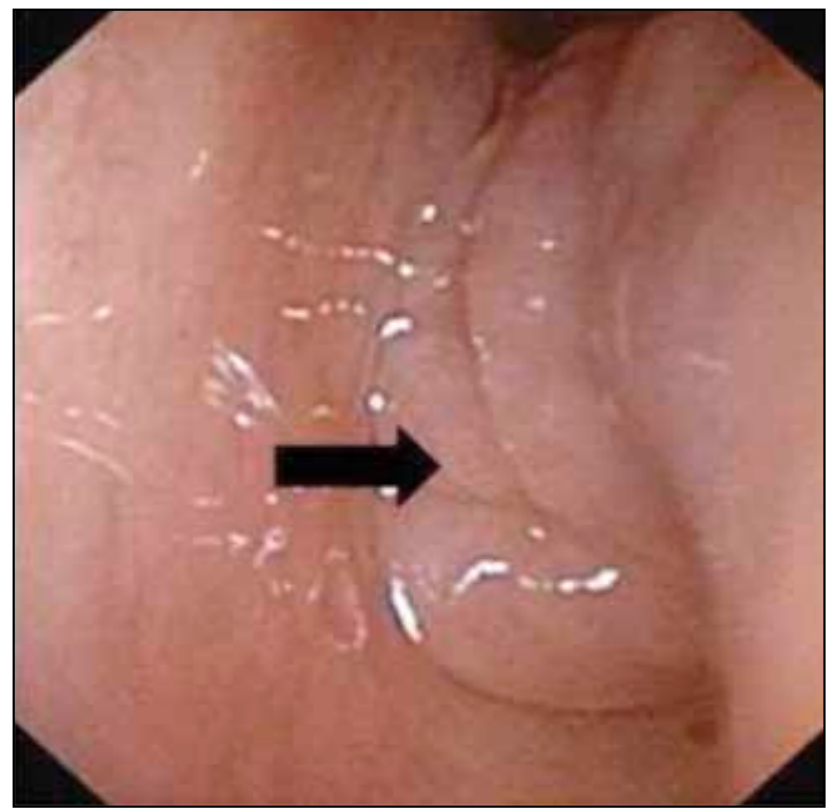

Figure 4 The mucosal hypertrophy of the posterior third of the inferior turbinate of the related nasal side (arrow). 


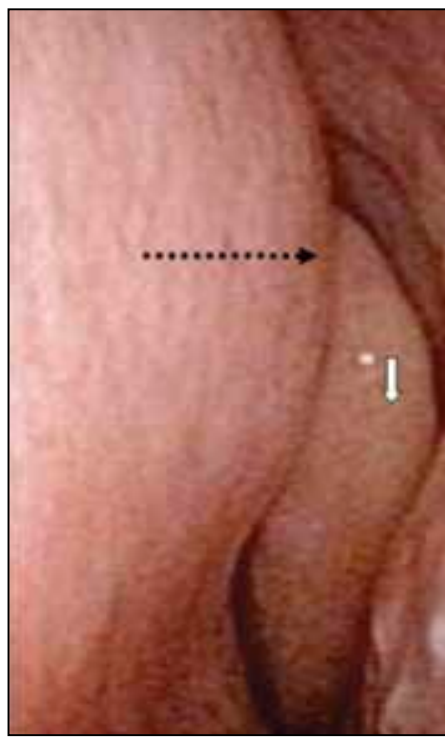

Figure 5 Left-sided type 3 ("septal belly"- arrow) which in this very case partly covers the clear vision to the middle turbinate (white arrow). In some cases, the convexity of the middle septal part is so emphasized that the middle turbinate cannot be seen at all, even during the endoscopy.
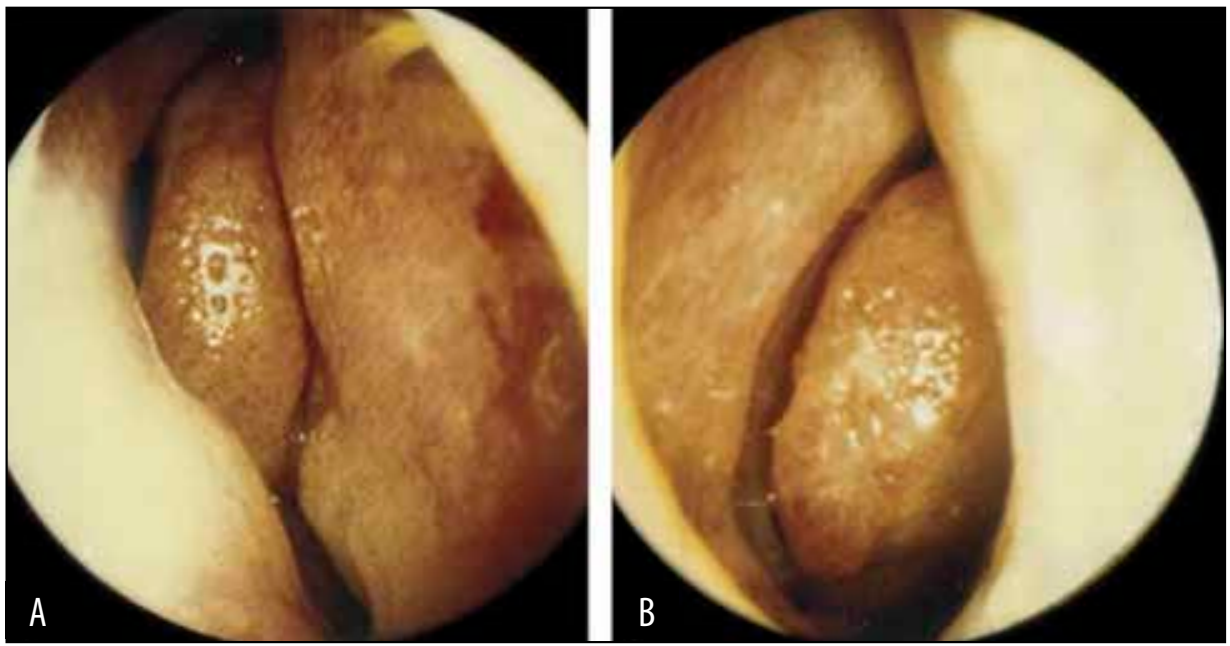

Figure 6 Type 4 nasal septal deformity. A right-sided type 3, i.e. convexity of the nasal septum hiding almost half of the anterior pole of the middle turbinate. They stay in a close contact. B left-sided type 2 , which in this very case is more pronounced in the upper part, but anyway is in a close contact to the anterior pole of the left inferior turbinate. This is an example of the so-called "S"-shaped (not at all "Z-shaped") nasal septum.
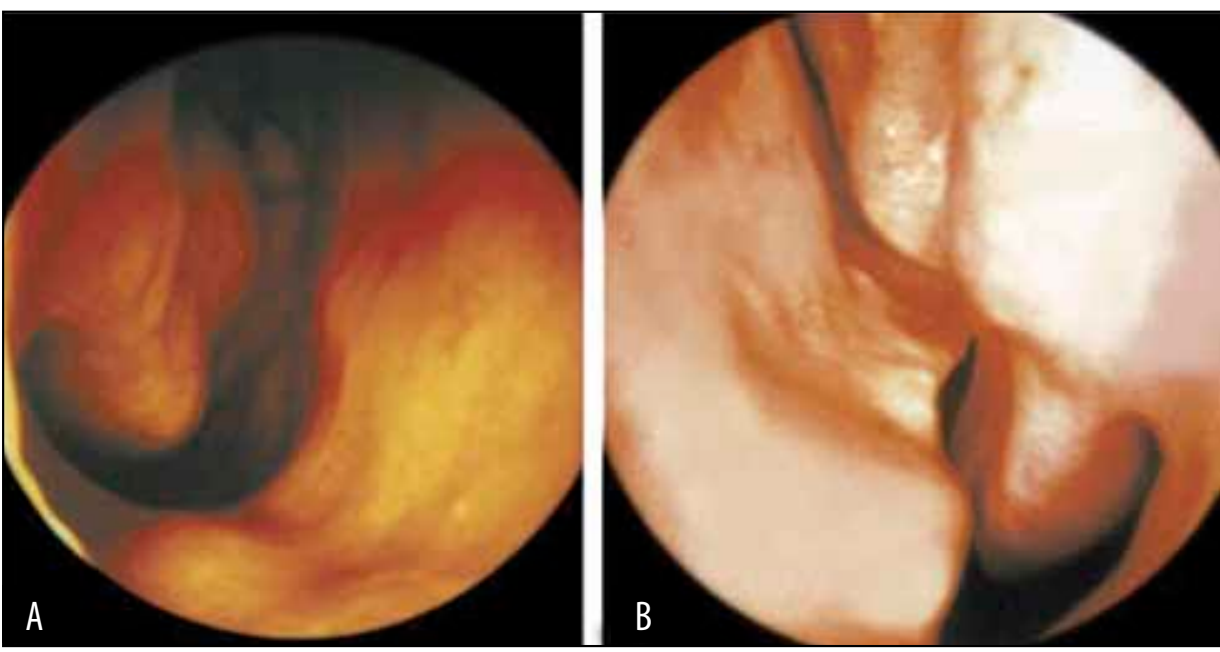

Figure 7 The close-up view of the left-sided type $5 \mathbf{B}$ with an obvious impaction of the tip of the deformity to the sphenopalatine region. The panoramic view of the right nasal cavity shows that the nasal septum $\mathbf{A}$ is almost ideally straight. 
tum, there is a horizontal groove (Figure $8 \mathrm{~A}, \mathrm{~B}$ ). The term "paradoxically" has been used on purpose since the term "hypertrophic" automatically makes one to imagine somewhat to be of a bigger size than usual. However, in the case of the intermaxillary bone, one should know that this bone has the shape of the letter " $\mathrm{Y}$ ". During the embryonic life, its lower part is supposed to be intruded and finally integrated between the palatal processes of the left and right maxilla. The final result, immediately after birth, should be the integration of three separate bones in one: the lower part of the intermaxillary ("Y"-shaped) bone and both palatal processes of the maxilla. Since the maxilla and the intermaxillary bone grow downwards and in an anterior direction, by the processes of resorption of the bone in the nose and apposition of the new bone over the hard palate and anterior surface of maxilla ${ }^{6}$, in case of type 6, it goes for the hypotrophic wing of the intermaxillary bone, which consequently remains in a higher position than the one that grows normally. The other side of the maxilla grows normally (that means downwards and anteriorly), producing the lowering of the related nasal floor and the other arm of the intermaxillary bone. This bone now becomes much a disfigured letter ' $Y$ ". Its lower arm enables sliding out of the inferior border of the growing quadrangular plate of the nasal septum, thus promoting the onset of the other anteriorly positioned "septal crest", which consists of the bony part (normally growing wing of the intermaxillary bone) and the lowest and most anterior part of the quadrangular, cartilaginous part of the nasal septum. Since the quadrangular plate now stays in an oblique position, while the hypo- trophic arm of the intermaxillary bone is still sticking laterally, the typical gutter between these two anatomical parts develops and crucially determines the type 6 nasal septal deformity. In the case presented in Figure 8 , it would be recorded as " $6 \mathrm{~L}$ ", meaning: type 6 with the groove on the left side. Finally, every single type 6 of nasal septal deformities is followed by the expected asymmetry of the hard palate (Figure 9). Type 6 can be perfectly recognized at the coronal CT scans as well (Figure10).

Type 7 ("crumpled septum") is very variable and it is presented by a combination of previously mentioned types with all their clinical implications (Figure 11). In fact, it always goes for a combination of one of two horizontal deformities (type 5 and/or type 6 ) with one of those belonging to the so-called vertical deformities (types 1, 2, 3 or 4).

Finally, it is practical to learn this classification by heart, maybe memorizing the schematic depiction in Figure 12.

\section{FORENSIC ASPECTS OF NASAL SEPTAL DEFORMITIES}

To be familiar with the classification of nasal septal deformities helps enormously in the situation when an ENT specialist is called as a court expert witness to give an expertise on whether or not a certain nasal or nasal septal deformity is connected to the incriminated trauma against someone's nose.

There is no doubt about the genesis of types 5 and 6 , since they have been scientifically proven as directly

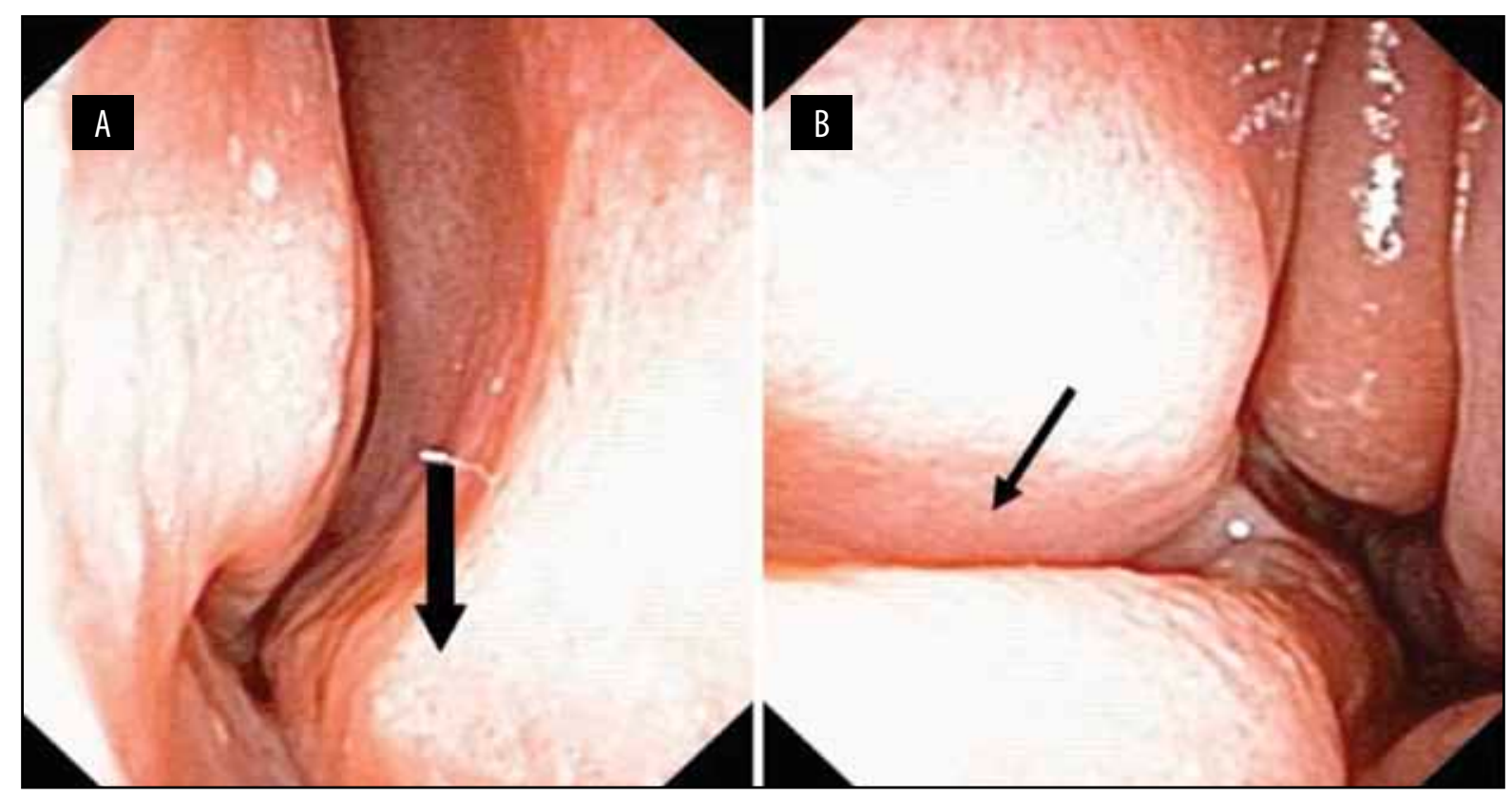

Figure 8 The clinical appearance of the type 6. A The basal crest in the right nasal cavity (black arrow); B There is a typical, deep groove (black arrow) in the left nose, at the correspondent level of the contralateral crest. 


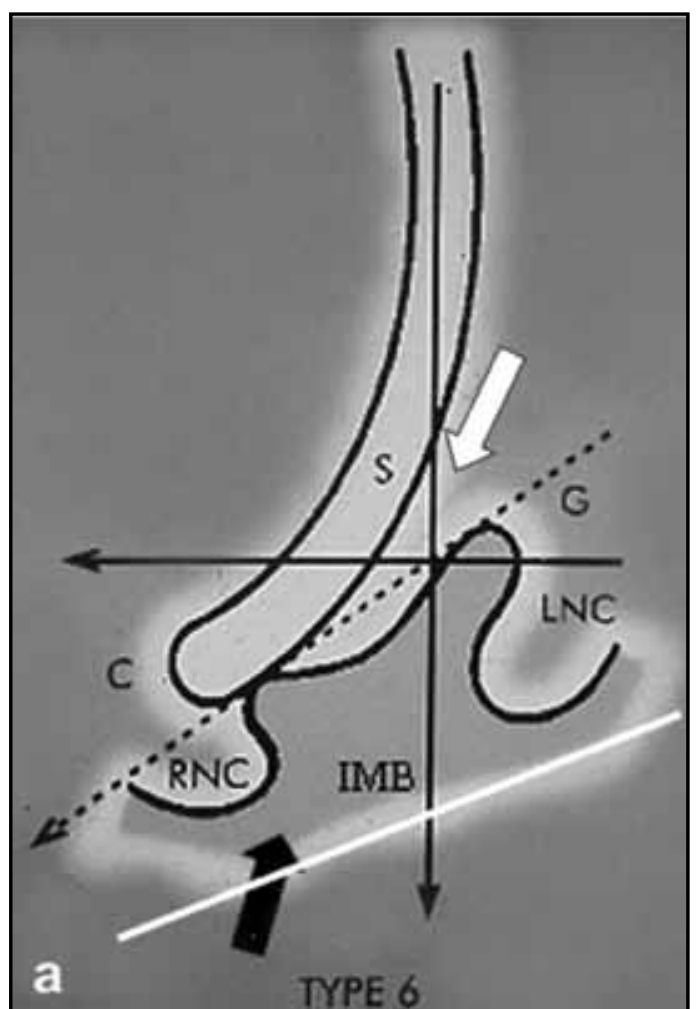

Figure 9 Left-sided type 6 nasal septal deformity. The groove is located on the left side (indicated by the white arrow). That is why this particular case was named "left-sided". The side of the gutter determines the side of this deformity. IMB-intermaxillary bone, RNC-right nasal cavity, LNC-left nasal cavity, S-septum (quadrangular cartilaginous plate), C-crest, G- the resultant of the forces (dotted arrow) directing the way of the slipping out of the inferior border of the nasal septum. The white line shows the asymmetry of the hard palate.

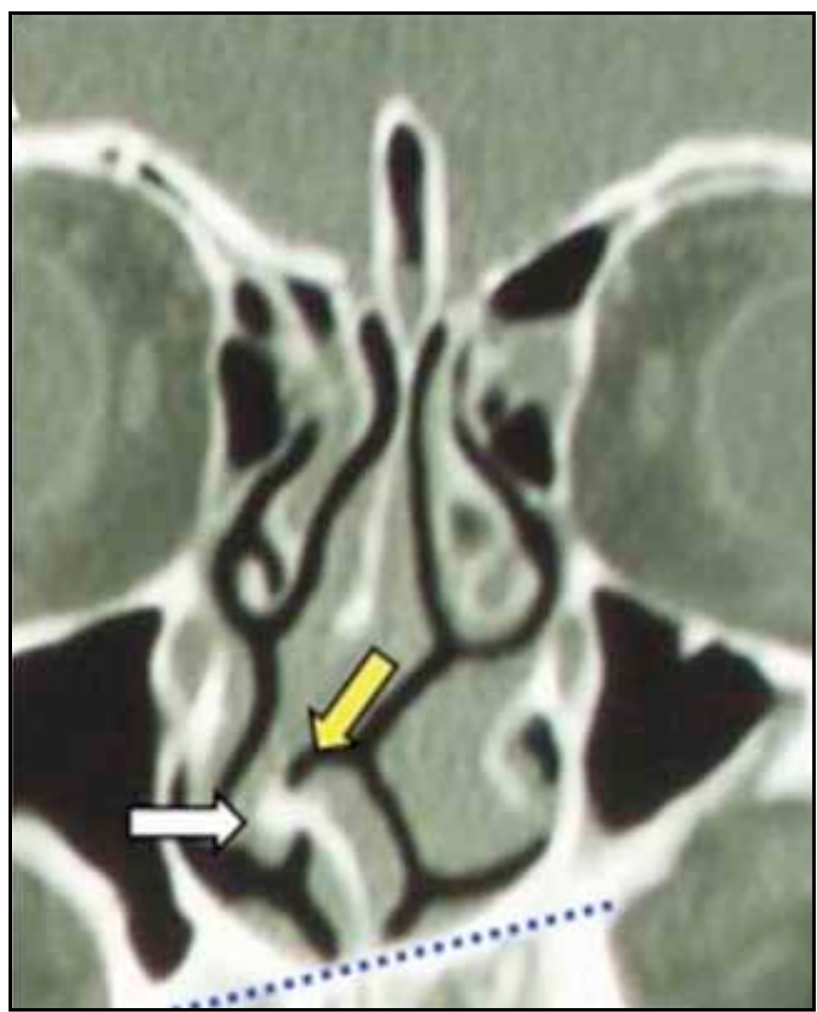

Figure 10 Coronal CT-scan of the paranasal sinuses. Septal deformity type 6 is clearly recognizable with typical groove (yellow arrow) and basal crest (white arrow). Dotted gray line shows asymmetry of the nasal floor, which is always found in this type of septal deformities.

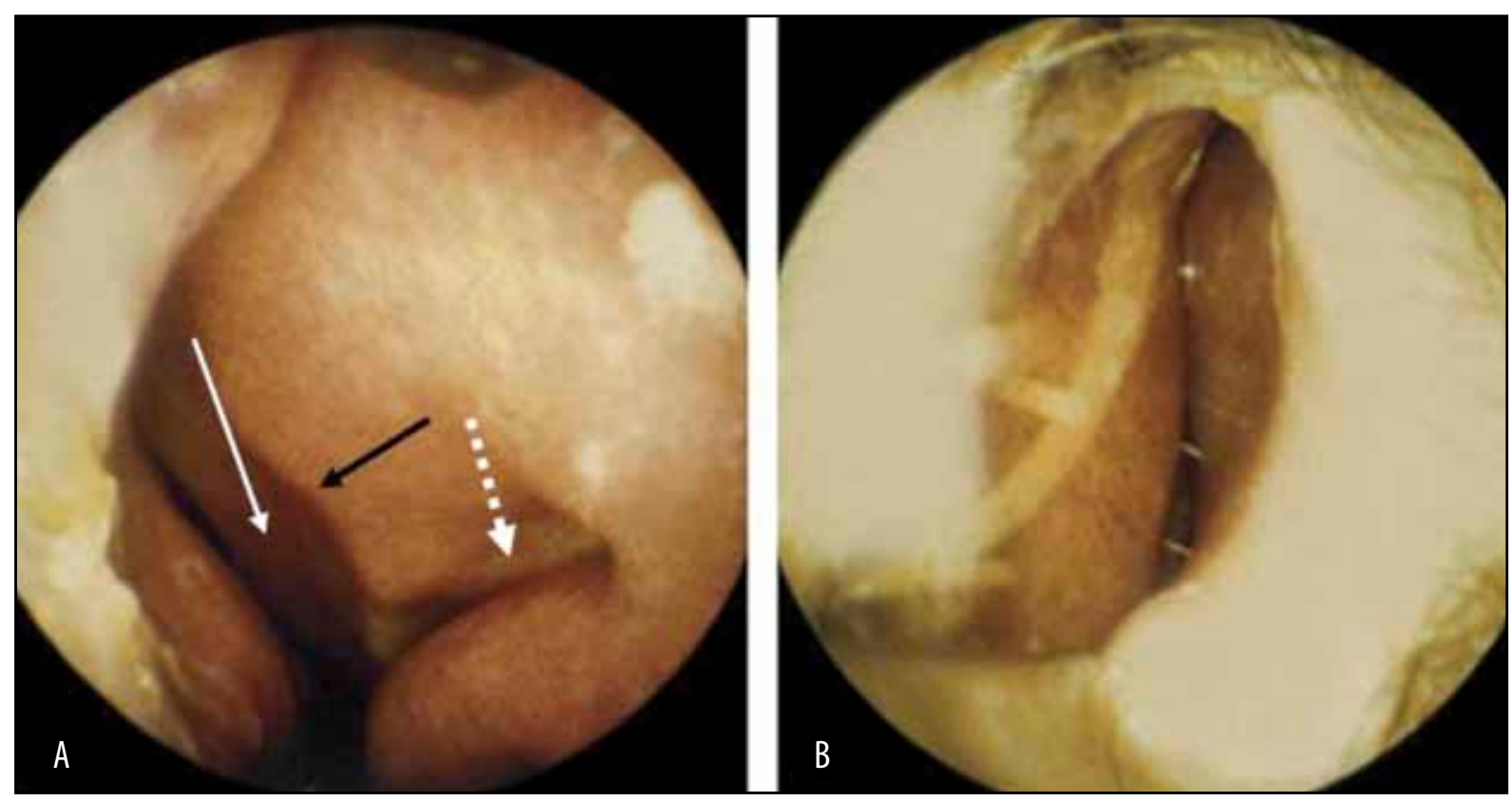

Figure 11 Type 7 nasal septal deformity. AThe right side of the septum shows obvious signs of the groove (dotted arrow), typical for type 6, but there is also a contour which resembles very much type 2 (black arrow). Very posterior parts of the septum seem to be formed like type 5 (white arrow); B the left side of the septum shows typical, obstructive type 2 which closely interferes with both the anterior pole of the inferior turbinate and the limen nasi. 


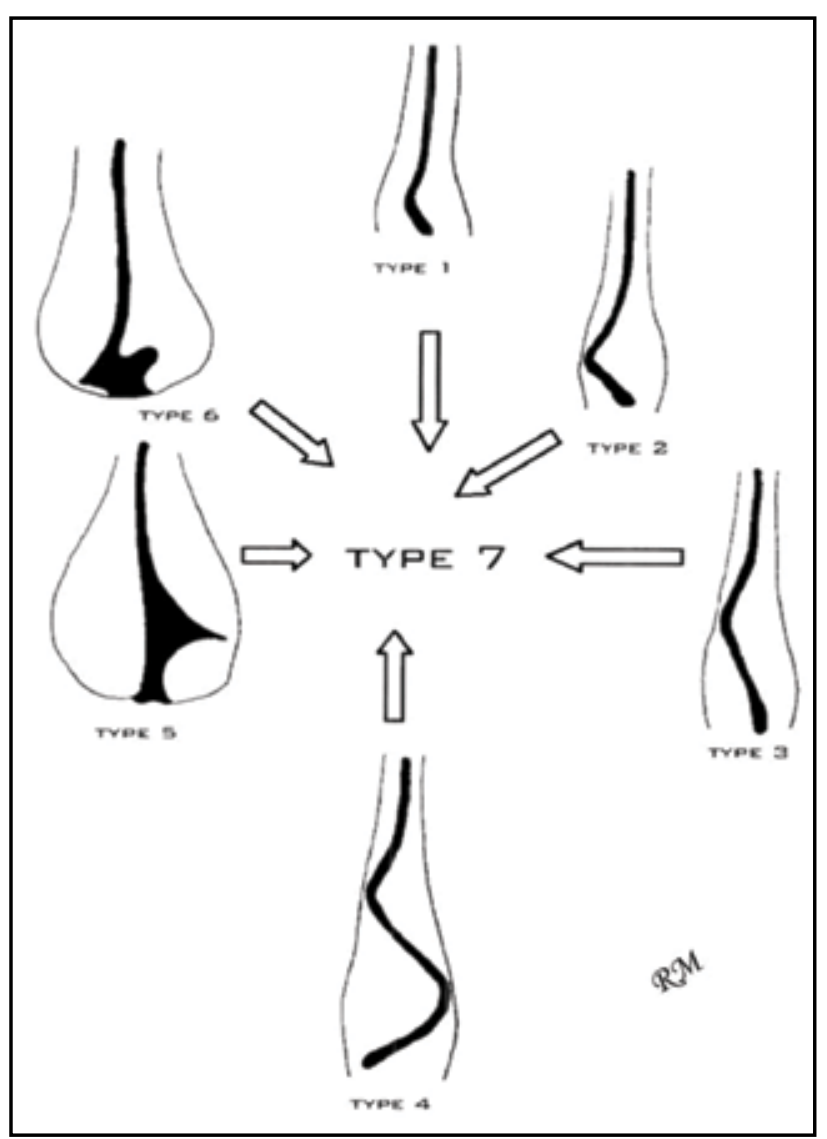

Figure 12 Schematic depiction of Mladina classification of the nasal septal deformities.

inherited. As a proof for the judge, for the members of the jury and/or, in complex cases, even the members of the court chamber, an endoscopic examination of the victim's nose could be transmitted in real time to the screen in the courtroom, as to clearly demonstrate the shape of the nasal septum of the victim and his or her closest relatives. There is no way to fail in successfully representing the existence of the same type of the nasal septal deformity in the victim and his or her closest relatives, be it in case of type 5 or type 6 .

One issue, however, should be kept in mind prior to the demonstration: the side of the deformity and its intensity are not the matter to be inherited, but the typical shape absolutely is.

The nasal septal deformities that could be related to the trauma against the nose are those with the "vertical" deflection, like types 1, 2, 4 and 7. Types 1 and 2 differ only regarding the intensity, otherwise they are almost identical. These two types are characterized by the deflection of the cartilaginous septum (anterior part of the quadrangular plate) in the closest neighbourhood of the limen nasi. Type 1, naturally, demonstrates only slight deflection (please refer to the Figure 1). In fact, it goes for the vertical ridge like in the case of type 2 , but type 2 in most of the cases is such an emphasized deformity that it can reach even the inner surface of the lateral nasal wall and thus, from the physical point of view, can remarkably narrow or even totally block the air passage on the related nasal side (please refer to the Figures 2 and 3 ). One should not forget that one of the consequences of type 2 could be also the hypertrophy of the posterior wall of the related inferior turbinate (Figure 4), which additionally compromises the already disturbed passing of the airstream through this side of the nose.

Intraoperative experiences and histological studies showed that the most prominent line of such emphasized deflections of the septal cartilage can be clearly identified, the so-called "green stick fracture" (Figure $13 \mathrm{~A}, \mathrm{~B})$, which means that there are no clear signs of the cartilaginous tissue disruption, or vice versa: with more than clear cartilaginous disruption (Figure 14).

In most of the cases, the incriminated trauma against the nose happened time ago, therefore even the connective tissue envelope around the fracture line can be easily identified during the surgery. All experienced and skilled nasal surgeons know these facts very well.

In general, type 1, and particularly type 2 can be connected to the trauma against the nose especially if it has come in anterior-posterior direction or, rarely, in the latero-lateral direction (fist-fighting, sports or traffic accidents, for instance). In cases of latero-lateral direction, nasal septal deformities types 1 or 2 are always located at the opposite side of the side from which the punch came. That is why in cases of leftsided type 2 the punch most probably came from the victim's right side, which, in addition, suggests that the assailant most probably was a left-handed person. This fact could sometimes help the police investigators to narrow the circle of the suspicious assailants.

As to the type 4, the court expert witnesses should bear in mind that this type can also be considered as a consequence of the trauma against the nose, but only partly since it consists of type 3 at one side, and type 2 on the opposite side. Type 3 has been excluded as a deformity of the traumatic origin unless there are not the obvious proofs of the fracture of the nasal bones whose appearance corresponds with this type of nasal septal deformity.

Type 5 and 6 definitively are not the consequence of any kind of trauma against the nose; they are considered to be directly inherited from one generation in the family to the next one. Finally, since type 7 is a variable combination of previous types, it should be studied by the court expert witness with a great caution. To give a trustworthy and correct report to the court, a high degree of knowing of the Mladina classification is required. None of the other classifications published so far gives the opportunity to precisely distinguish between particular types of nasal septal deformities and analyze them correctly from the forensic point of view. In such cases, it is strongly recommended to use, besides classical examination 


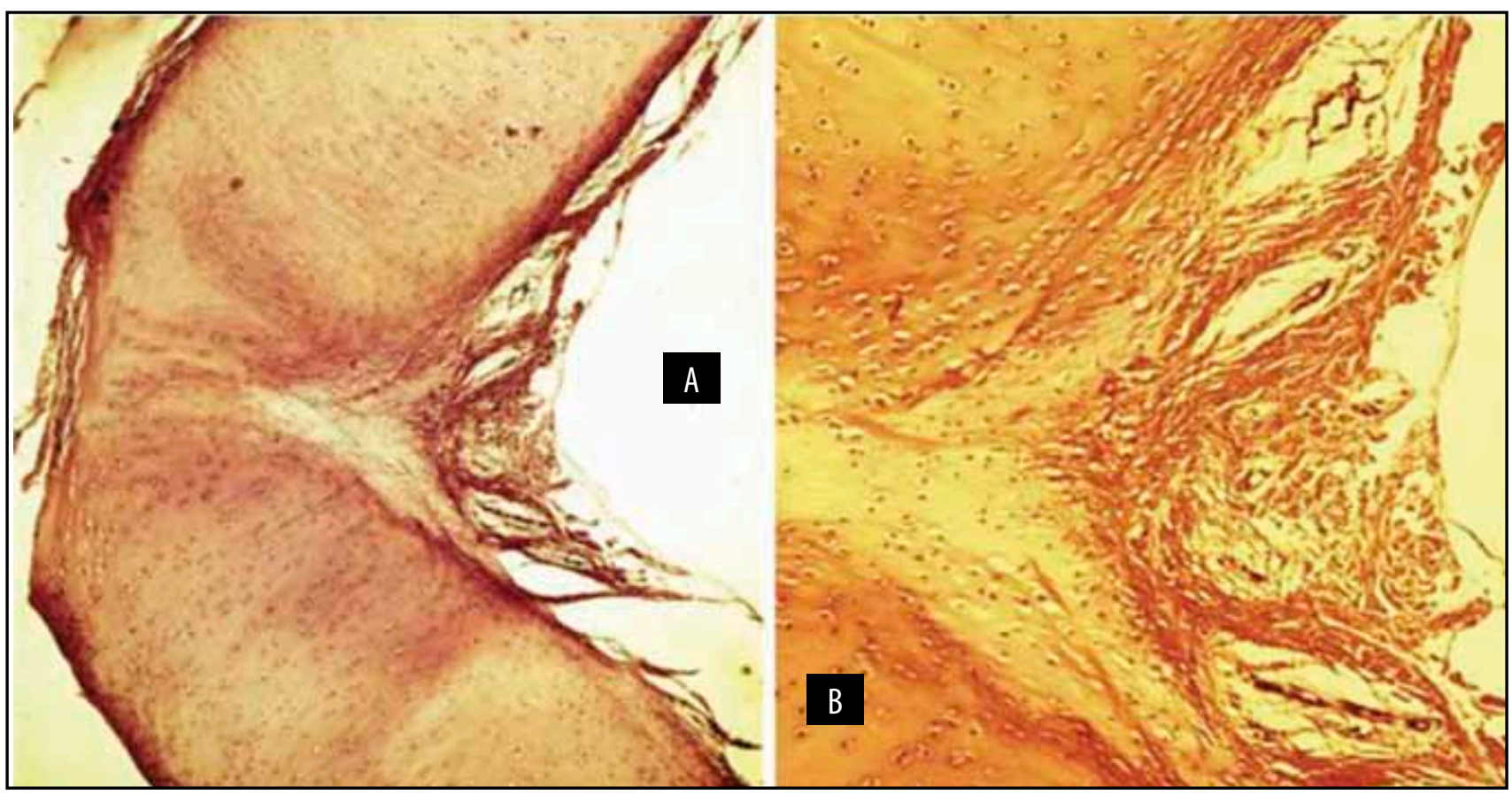

Figure 13 A, B. Histology of the septal cartilage (horizontal section!) through the right-sided type 2 septal deformity of an adult patient. Despite an emphasized angulation, there are no signs of discontinuity of the cartilage. B) close-up view of the angulation shows typical appearance of the so-called "green stick fracture": no tissue discontinuity (no gap), and the high amount of chondrocytes can be clearly seen invading the damaged place.

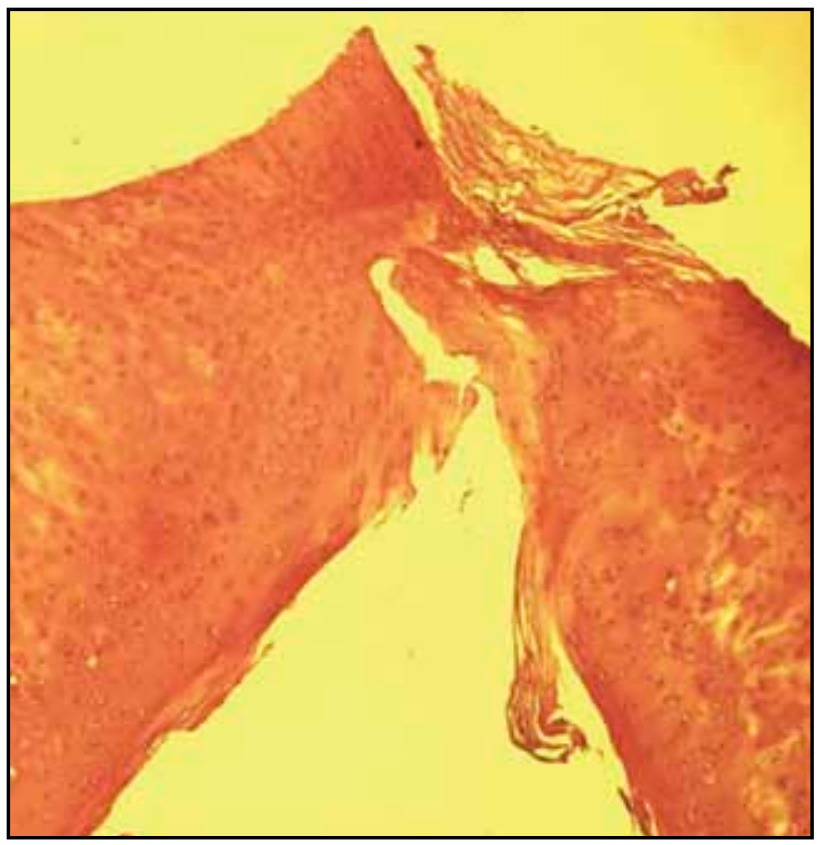

Figure 14 Histological appearance of the obvious discontinuity of the septal cartilage after serious trauma against the nose.

tools, also the CT-scanning, both in axial and coronal projections.

The court expert witnesses should be particularly aware of some types of the external nose deformities, since they, at the very first sight, might be supposed to be associated with the incriminated nasal septal deformity. Fortunately, there are only three such situa- tions: "S" or "reverse S-shaped nose" (Figure 15), "Cshaped" or "reverse C-shaped" noses (Figure 16), and the "saddle nose" (Figure 17). The ordinary X-rays of the nasal bones are highly recommended in all described external deformities. Both anterior-posterior and latero-lateral projection are desired.

\section{CONCLUSIONS}

The assessment of the nasal septal deformities from the forensic point of view is quite simple, provided that the court expert witness is familiar with the classification of the nasal septal deformities, mechanisms of their development and their onset. Two types are never the consequence of trauma against the nose: type 5 and type 6 .

In most of the cases, this also concerns type 3 . This type as well as type 7 require the latero-lateral and anterior-posterior X-rays of the nasal bones in cases when the nasal pyramid is concurrently deformed. Types 1 and 2 can be connected to trauma against the nose as well.

Funding sources: None. There are no financial disclosures of the authors.

Conflict of interest: The authors have no conflict of interest.

Contribution of authors: All authors have equally contributed to this work. 


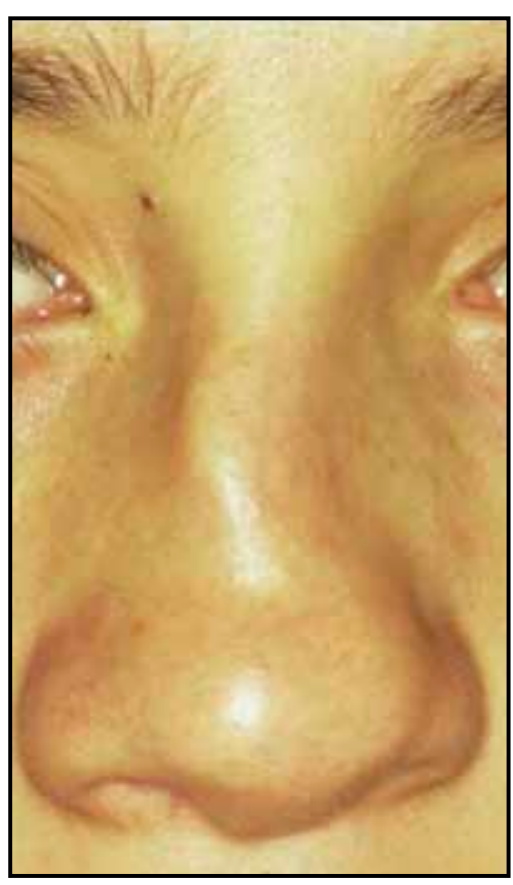

Figure 15 The S-shaped external nose.

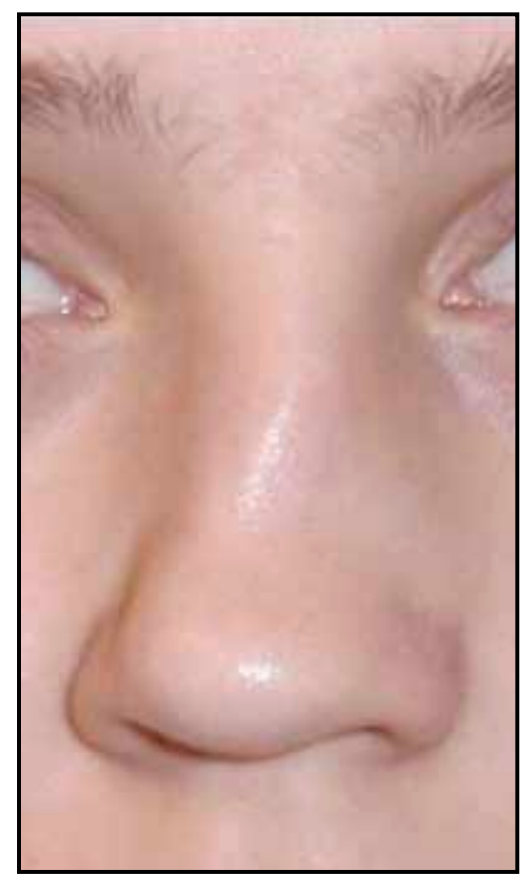

Figure 16 Typical "reverse-C"-shaped external nose. The trauma came from the patient's left and anterior side (the hard punch by the teammate's elbow during the handball match).

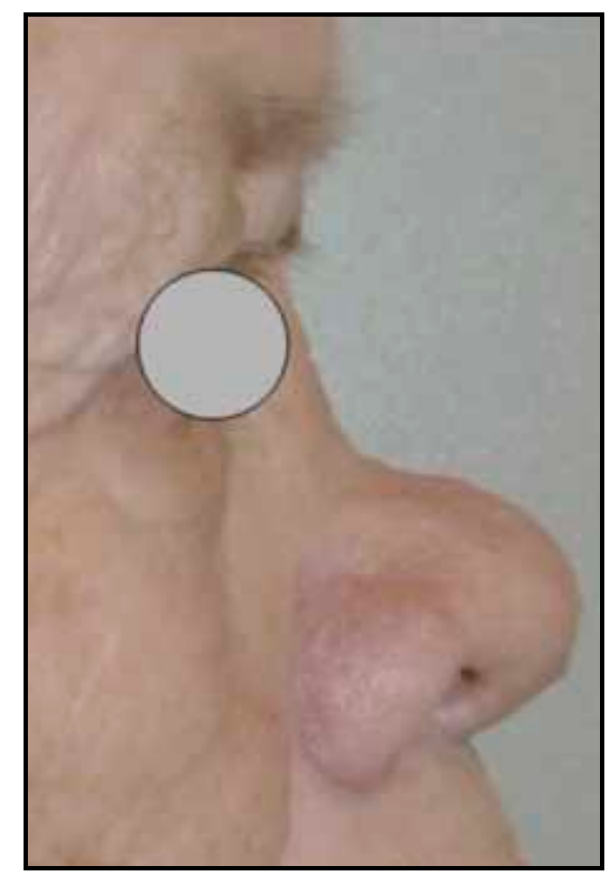

Figure 17 Typical saddle nose after the trauma during childhood.

\section{REFERENCES}

1. Mladina R. The role of maxillar morphology in the development of pathological septal deformities. Rhinology. 1987;25(3):199-205.

2. Verwoerd CD, Mladina R, Nolst Trenite GJ, Pigott RW. The nose in children with unilateral cleft lip and palate. Int J Pediatr Otorhinolaryngol. 1995;32 Suppl:S45-52.

3. Mladina R, Ostojić D, Koželj V, Heinzel B, Bastaić LJ. Pathological septal deformities in cleft palate children. L'Otorinolaryngologia Pediatrica. 1997;2-3:75-80.
4. Mladina R, Šubarić M. Are some septal deformities inherited? Type 6 revisited. Int J Pediatr Otorhinolaryngol. 2003;67:1291-94.

5. Mladina R, Skitarelić N, Vuković K, Subarić M, Carić T, Orihovac Z. Unilateral cleft lip/palate children: the incidence of type 6 septal deformities in their parents. J Craniomaxillofac Surg. 2008;36(6):335-40. DOI: 10.1016/j.jcms.2008.03.003. Epub 2008 May 2.

6. Enlow DH. Growth and remodeling of the human maxilla. Am J Orthod. 1965;51:446-64. 